\title{
Direito internacional de águas e soberania: velhas e novas antinomias
}

\author{
International law of waters and sovereignty: old and new antinomies
}

\author{
Jefferson Rodrigues de Quadros* \\ Erivaldo Cavalcanti e Silva Filho**
}

\section{Resumo}

As antinomias existentes entre o direito e a soberania não constituem discussões novas: remontam à própria formação do Estado. O direito internacional moderno, pautado por forte carga humanitária, reconhece a existência de bens jurídicos supranacionais, os quais não respeitam fronteiras, como o direito à água. O direito humano e universal ao acesso à água, instrumentalizado pelos fundamentos principiológicos do direito internacional de águas, como também pelos objetivos do desenvolvimento sustentável propostos pela ONU, por meio das premissas da Agenda 2030, enquanto plataformas jurídicas internacionais, resultaram por produzir proposições capazes de provocar uma novel discussão acerca das relações entre os Estados com as águas transfronteiriças. Os cursos de águas em bacias hidrográficas transfronteiriças desconhecem as fronteiras dos Estados, razão pela qual demandam a construção de modelos de gestão que, não raras vezes, encontram-se inviabilizados na seara da efetividade, especialmente em decorrência da complexidade de normas e procedimentos burocráticos estabelecidos pelos Estados que compartilham as suas bacias hidrográficas, o que, inexoravelmente, justifica a revisitação sobre o sentido de soberania no contexto contemporâneo. Assim, o objetivo deste artigo consiste em provocar uma reflexão sobre as antinomias existentes entre o direito internacional de águas e a soberania dos Estados, enquanto fatores de tensão comprometedores à governança hídrica e, consequentemente, à gestão nas bacias hidrográficas transfronteiriças. A metodologia de pesquisa empregada foi bibliográfica e documental, de natureza qualitativa, sendo utilizada a doutrina e a legislação especializada sobre soberania e direito internacional de águas.

Palavras-chave: Direito internacional de águas. Soberania. Bacias hidrográficas transfronteiriças. Gestão integrada de recursos hídricos. Governança hídrica.

\section{Abstract}

The antinomies between law and sovereignty are not new discussions: they go back to the very formation of the State. Modern international law, based on a strong humanitarian burden, recognizes the existence of supranational legal goods, which do not respect borders, such as the right to water. The human and universal right to access to water, instrumentalised by the fundamental principles of international water law, as well as by the objectives of sustainable development proposed by the UN through the premises of the Agenda 2030 as international legal platforms in the relation of State to water, have resulted in the production of propositions capable of provoking a newl discussion about the relations between States and transboundary waters. Water courses in transboundary river basins do not know the frontiers of the states, which is why they require the construction of management models that are often not feasible in the area of effectiveness, especially due to the complexity of established bureaucratic norms and procedures by the States that share their watersheds, which, inexorably, justifies the revisiting of the sense of sovereignty in the contemporary context. The objective of this article is to reflect on the antinomies between international water law and State sovereignty, as tensions that compromise

\footnotetext{
Doutorando em Estudos Amazônicos pela Universidad Nacional de Colombia (UNAL). Mestre em Direito Ambiental pela Universidade do Estado do Amazonas (UEA). Mestre em Direito das Relações Internacionais e da Integração na América Latina pela Universidad de la Empresa de Montevidéu/Uruguai (UDE). Especialista em Direito Penal Econômico e Europeu pela Universidade de Coimbra/Portugal (UC). Especialista em Direito Penal e Empresarial pela Pontifícia Universidade Católica do Rio Grande do Sul (PUCRS). Professor do Curso de Direito da Universidade do Estado do Amazonas (UEA). Tabatinga - AM - Brasil. E-mail: quadros.jefferson@gmail.com.

** Doutor em Desenvolvimento Sustentável e Mestre em Ciência Política. Coordenador do Programa de Mestrado em Direito Ambiental - PPGDA da Universidade do Estado do Amazonas (UEA). Pesquisador líder do Diretório de Grupos de Pesquisas do CNPq em Direito de Águas. Consultor Ad-Hoc da Coordenação de Aperfeiçoamento de Pessoal de Nível Superior - Capes e da Fundação de Amparo à Pesquisa do Estado do Amazonas - FAPEAM. Membro e avaliador do CONPEDI - Conselho Nacional de Pesquisa e Pós-graduação em Direito, do Conselho Científico e do banco de especialistas da ABRADE - Associação Brasileira de Direito Educacional. Manaus - AM - Brasil. E-mail: erivaldofilho@hotmail.com.
} 
water governance and consequent management in transboundary river basins. The research methodology used was the bibliographical and documentary, of a qualitative nature, using the doctrine and specialized legislation on sovereignty and international water law.

Keywords: International water Law. Sovereignty. Cross-border watersheds. Integrated water resources management. Water governance.

\section{Introdução}

A dicotomia entre o direito e a soberania não constitui uma discussão nova e peculiar de um mundo globalizado. Desde os primeiros lineamentos originários da formação do Estado de Direito, enquanto ente soberano e reconhecido pelo direito internacional, até os dias atuais, se questiona: quem é que orienta quem? É o direito que estabelece os limites e poderes à soberania ou é a soberania que estabelece os limites ao direito? O poder, efetivamente, emana do povo, como expressão da soberania? A partir dessas indagações preliminares, podem ser pensadas outras tantas, todavia, como o propósito deste trabalho reside na análise da antinomia entre o direito internacional águas e a soberania, limitar-se-á a este espectro temático, cuja relevância se justifica pela natureza difusa do bem jurídico humanitário objeto de disputa entre ambos: as águas transfronteiriças.

O direito internacional de águas, enquanto conjunto de normas e princípios que regulam a relação dos Estados com as águas, tem por finalidade basilar viabilizar o direito humanitário universal acerca do acesso e distribuição da água em quantidade e qualidade às pessoas. Dessa forma, o que justifica a existência do direito internacional de águas é o direito humano e universal à água. Com o escopo de alcançar o direito - humanitário - à água, resultaram produzidos diversos Tratados, bem como realizadas Convenções internacionais cujas temáticas se propuseram a discutir sobre a criação de princípios e regras para o fim de regulamentar a relação entre os Estados com as águas, em especial, as compartilhadas com outros Estados.

A evolução do direito internacional de águas, fundamentado em diversos princípios, dentre estes, o da participação e da cooperação internacional, culminou no desenvolvimento de um novo modelo de organização a fim de orientar os Estados que compartilham as suas bacias hidrográficas com outros Estados na gestão das águas de cursos transfronteiriços, denominado como Gestão Integrada de Recursos Hídricos Transfronteiriços (GIRHT). Esse modelo representa o que existe de mais democrático e moderno no sistema de gestão de bacias hidrográficas transfronteiriças concebido até hoje, demandando uma série de pressupostos de natureza política, científica, técnica e operacional, sendo alimentado por conhecimentos interdisciplinares de diversas áreas da ciência. Dentre os pressupostos para a viabilização da GIRHT, encontra-se a governança hídrica, enquanto expressão do princípio da participação inerente ao direito internacional de águas. Desta feita, com fundamento em diversos diplomas internacionais, a GIRHT passou a se tornar tema obrigatório nas agendas políticas internacionais, razão pela qual foi elencada como um dos objetivos do desenvolvimento sustentável (6.5 ODS) estabelecidos na Agenda 2030, a qual foi ratificada e internalizada às políticas programáticas de diversos Estados.

Todavia, pelo fato da temática sobre o domínio das águas compartilhadas pelos Estados representar não apenas a exteriorização das suas soberanias em assuntos estratégicos de segurança nacional e de importância geopolítica no cenário internacional, a efetividade da governança hídrica, com a participação da sociedade na gestão das águas transfronteiriças, conforme preconizado pelo direito internacional de águas, encontra obstáculos que parecem intransponíveis em razão da dimensão dos entraves burocráticos estabelecidos pelos ordenamentos jurídicos internos dos Estados.

Dogmaticamente concebido como expressão de independência política e territorial de um Estado no plano interno e externo, o conceito de soberania oscilou ao longo da história, ora dilatando, ora reduzindo os poderes de Estado. No contexto contemporâneo, está passando por novas revisões, decorrentes das crises dos Estados nacionais em razão da globalização e, especialmente, pela amplitude da universalização dos direitos humanos, cuja dimensão alberga, inclusive, o direito à água. 
Nessa esteira humanitária e diante de um mundo globalizado, permite-se conceber que as águas das bacias hidrográficas que têm curso transfronteiriço não poderiam se sujeitar ao monopólio das decisões governamentais de um único Estado como expressão da sua soberania nacional, pois essas águas representam bem jurídico digno de proteção por sua essência supranacional e supraindividual. Entendese que a água é bem jurídico titular de direitos, inclusive, hierarquicamente, superior aos demais direitos humanos de primeira geração, uma vez que a água representa fonte de vida em todas as suas formas e, sem vida, não existe direito humano ou ecológico suscetível de ser protegido. Portanto, pelo fato de a água representar condição inafastável para a existência de vida, animal ou vegetal, ela precede a existência de todos os demais direitos, inclusive, sobre os direitos humanos. Por isso, apresenta-se justificada uma visão biocentrista, a qual refuta a soberania nacional como expressão de legitimação dos Estados para violarem regras de direito internacional de águas e, consequentemente, frustrarem o direito humano e universal à água.

Conforme destacado anteriormente, para efeito do desenvolvimento de uma GIRHT, apresenta-se necessária a constituição de um modelo de governança hídrica efetivamente participativo; e aqui se encontra o ponto nevrálgico do presente estudo: as novas tensões entre o direito internacional de águas e as soberanias dos Estados, pois as políticas hídricas decorrentes das soberanias dos Estados que compartilham as suas bacias hidrográficas com outros, não raramente, concorrem para a violação do direito de águas, como também se apresentam como obstáculos à participação da sociedade e, consequentemente, à governança hídrica nessas bacias hidrográficas, inviabilizando a gestão integrada das mesmas.

Assim, desprovido do propósito de esgotar o tema sobre as antinomias entre o direito internacional de águas e a soberania, o presente artigo tem como objetivo fazer um convite à reflexão sobre o conflito contemporâneo existente entre o direito internacional de águas e os obstáculos opostos pelas soberanias dos Estados em relação à governança hídrica nas bacias hidrográficas transfronteiriças.

Para efeito do desenvolvimento do presente artigo, na primeira etapa analisam-se algumas peculiaridades acerca do sentido de soberania dos Estados no contexto contemporâneo; em um segundo momento, apresenta-se uma breve aproximação ao direito internacional de águas, dispensando-se ênfase aos princípios da proteção, cooperação internacional e participação; em seguida, em terceiro momento, analisase a importância da governança hídrica nas bacias hidrográficas transfronteiriças enquanto expressão do princípio da participação para a Gestão Integrada dos Recursos Hídricos Transfronteiriços (GIRHT). Por fim, considerando as temáticas abordadas, é realizada análise conclusiva sobre o reaparecimento de velhas antinomias: de um lado, o direito internacional de águas, dotado de robusto arcabouço jurídico e principiológico; e, de outro, a soberania dos Estados em relação ao domínio das águas compartilhadas, cujo curso forma as bacias hidrográficas transfronteiriças.

Com o propósito de balizar a pesquisa, empregou-se o método indutivo, mediante investigação bibliográfica e documental realizada na doutrina especializada e em diplomas de direito internacional de águas. Trata-se de um estudo exploratório e qualitativo, capaz de fomentar um objeto de pesquisa ainda pouco investigado pela academia, podendo proporcionar maiores esclarecimentos sobre os efeitos da soberania dos Estados em relação à gestão hídrica nas bacias hidrográficas transfronteiriças.

\section{Reflexões sobre o sentido de soberania no contexto contemporâneo}

Permite-se conceber que a soberania é uma ficção político-jurídica, cuja dimensão sempre esteve presente ao longo da história das formações dos Estados, desde o absolutismo até os dias atuais: no absolutismo, representada pela figura do soberano, como ser humano designado por Deus, sendo o legitimado para estabelecer a "ordem divina na Terra"; no decurso do século XVI, como consequência das rupturas das estruturas colonialistas que existiam sobre diversos territórios, permitindo a formação de Estados independentes; sendo reconfigurada, no limiar do século XVIII, pelos prismas liberais da Revolução Francesa; e prolongando-se até os dias atuais, constituindo-se como elementar para a formação dos Estados.

A soberania, concebida como poder necessário e indivisível para a mantença do Estado, teve como um dos seus mais célebres fundadores Bodin, que, em 1576, escreveu os Seis Livros da República, sustentando a soberania como "elemento intrínsico do Estado". 
Para Canotilho (2003, p. 89), o Estado é dotado de qualidades que o distinguem de outros poderes e organizações de poder, elencando, em primeiro lugar, "o poder soberano". Para o referido catedrático da Universidade de Coimbra (2003, p. 90):

\begin{abstract}
A soberania, em termos gerais e no sentido moderno, traduz-se num poder supremo no plano interno e num poder independente no plano internacional. Se articularmos a dimensão constitucional interna com a dimensão internacional do Estado poderemos recortar os elementos constitutivos deste: (1) poder político de comando; (2) que tem como destinatários os cidadãos nacionais (povo=sujeitos do soberano e destinatários da soberania); (3) reunidos num determinado território.
\end{abstract}

Assim, segundo se observa nos ensinamentos de Canotilho, a soberania está intrinsecamente ligada ao poder político de comando legitimado pela delegação de uma representação política feita pelo povo de um determinado território, tendo como destinatários os cidadãos nacionais.

Marcello Caetano (1970, v .I, p.169), por sua vez, entende que a soberania significa poder político supremo e independente: supremo, porque "não está limitado por nenhum outro na ordem interna"; e independente, porque, "na ordem internacional, não tem de acatar regras que não sejam voluntariamente aceitas e está em pé de igualdade com os poderes supremos dos outros povos".

Diz e Martins (2015, p. 638), por seu turno, quando discorrem sobre as acepções do conceito de soberania, dispensam atenção a sua classificação, averbando o seguinte:

A soberania pode ser observada sob os prismas da soberania interna e da soberania externa. Sob o ponto de vista da soberania interna, apresenta-se como um conceito jurídico social, isto é, considera-se soberana a organização estatal cujo ordenamento jurídico é dotado de imperatividade, superioridade e supremacia, tornando o poder estatal sobreposto e incontrastável aos demais poderes sociais que Ihe ficam subordinados. É o predomínio do ordenamento estatal em determinado território, em relação à população ali existente, sob qualquer outra espécie de ordenação social. Sob o prisma da soberania externa, apresenta-se como a capacidade, o poder reconhecido às organizações estatais para impor seu ius imperius, para fazer frente as demais organizações estatais soberanas, não admitindo que outras formas de manifestação de poder externas determinem, condicionem ou influenciem direta ou indiretamente na elaboração das políticas internas do Estado e no processo de tomada de decisões. Está, portanto, diretamente ligada à ideia de independência, de capacidade de autodeterminação da organização estatal.

Reale (2002, p. 127), por sua vez, discorrendo sobre a soberania interna enquanto plataforma de organização de Estado, afirma que a soberania constitui o "um poder de organizar-se juridicamente e de fazer valer dentro do seu território a universalidade de suas decisões nos limites dos fins éticos de convivência".

Todavia, no contexto hodierno, pautado pela globalização e dinamismo das relações internacionais, o sentido de soberania, tanto interna quanto externa, ganhou nova roupagem, acompanhando a crise do Estado de bem-estar social, permitindo a transformação de plataformas políticas e ideológicas, materializadas por meio da relativização de direitos e obrigações decorrentes de condicionantes políticas externas. Nesse sentido, segundo Dantas (2009, p. 13):

[...] a própria noção de Estado, de base nacional-territorial, sofre grande impacto com tantas transformações e o due da estatalidade e Soberania, que sempre foram tidas como noções essencialmente vinculadas, são confrontadas com novos atores do cenário internacional que prescindem da figura dos Estados e da qualificação de soberanos.

A globalização não respeita fronteiras nem limites, razão pela qual dispõe de capacidade para influenciar nos rumos das políticas públicas internas e externas dos Estados, as quais representavam expressão das suas soberanias. Dispensando severas críticas à globalização ao acusá-la de manipular os Estados como instrumentos para alcançar os seus objetivos econômicos, Bauman (1999, p. 74) afirma:

No cabaré da globalização, o Estado passa por um strip-tease e no final do espetáculo é deixado apenas com as necessidades básicas: seu poder de repressão. Com sua base material destruída, sua soberania e independência anuladas, sua classe política apagada, a nação-estado torna-se um mero serviço de segurança para as mega empresas. Os novos senhores do mundo não tem necessidade 
de governar diretamente. Os governos nacionais são encarregados da tarefa de administrar os negócios em nome deles.

Com efeito, a globalização mudou o mundo, bem como as relações de soberania entre os Estados, uma vez que eles dependem mais de múltiplos interesses e acontecimentos externos para a promoção das suas políticas socioeconômicas do que das suas próprias forças institucionais.

Nesta esteira, Ferrajoli (2002, p. 28) descreve a soberania moderna como ficção política, uma vez que a essência da expressão encontra-se negada por diferentes realidades sociopolíticas e jurídicas, tanto no plano interno como no plano internacional, ao afirmar que a soberania "encontra-se visivelmente em declínio pelas tendências políticas atuais da comunidade internacional”. São inúmeras as demandas políticas estabelecidas pela comunidade internacional: o desenvolvimento econômico, a segurança, os direitos humanos, a proteção ambiental, entre outros. Dentre as "políticas atuais da comunidade internacional" apontadas por Ferrajolli (2002), permite-se conceber que as políticas de gestão dos recursos hídricos transfronteiriços se encontram inseridas, uma vez que o direito à água constitui direito humano, universal, difuso e supranacional, portanto, digno de ser tutelado pelo direito internacional, o que justificaria a limitação da soberania dos Estados nas bacias transfronteiriças.

O princípio da soberania permanente dos Estados sobre os recursos naturais foi objeto de diplomas internacionais, sendo consagrado no Princípio 21 da Convenção de Estocolmo, bem como no Princípio $2^{\circ}$ da Declaração do Rio, os quais estabelecem que: "os Estados têm o direito soberano de explorar seus próprios recursos de acordo com suas políticas ambientais e de desenvolvimento, em conformidade com a Carta das Nações Unidas e com os princípios de direito internacional”. Defendendo a limitação da soberania dos Estados em relação à exploração dos recursos naturais compartilhados quando trata sobre o princípio da soberania permanente, adotado pelo Princípio 21 da Convenção de Estocolmo e pelo Princípio $2^{\circ}$ da Declaração do Rio, Silva (2010, p. 106) averba que:

\begin{abstract}
O alcance desse princípio é, todavia, limitado, por um lado pelos compromissos internacionalmente assumidos em tratados multilaterais, regionais ou bilaterais, como também pelo costume internacional, e, por outro lado, por uma série de princípios do direito ambiental internacional, como o princípio da prevenção e da precaução, que orientam as ações dos Estados e fundam as bases da cooperação internacional em matéria ambiental. Ele também é limitado pela própria interdependência dos ecossistemas e dos recursos naturais compartilhados. Assim, há tratados que preveem a repartição de recursos, como é o caso: a) da Convenção sobre a Diversidade Biológica; b) da Convenção das Nações Unidas sobre Direito do Mar. Além disso, há a obrigação de assegurar-se de que as atividades que se levem a cabo, dentro de sua jurisdição, ou sob seu controle, não prejudiquem o meio ambiente de outros Estados ou de zonas situadas fora de toda jurisdição nacional (cf. território e poluição transfronteiriça e zonas comuns, patrimônio comum da humanidade e preocupação comum).
\end{abstract}

O conceito dogmático de soberania no plano jurídico-teórico coloca-a em um patamar de submissão ao direito. Todavia, na realidade, e abstraindo o seu sentido pseudoconceitual, a soberania está sempre a desafiar o direito, uma vez que a principal característica da soberania é a inobservância de limites das regras. Nesse sentido, afirma Ferrajoli (2002, p. 44): "[...] a soberania é a ausência de limites e de regras, ou seja, é o contrário daquilo em que o direito consiste. Por essa razão, a história jurídica da soberania é a história de uma antinomia entre dois termos - direito e soberania -, logicamente incompatíveis e historicamente em luta entre si".

Com efeito, compartindo com o entendimento de Ferrajoli (2002) de que são as características sociopolíticas e jurídicas, enquanto elementos determinantes, que vão nortear a soberania de cada Estado, entende-se que o sentido de soberania resultou vulnerabilizado pelos processos de globalização e pelas políticas de universalização dos direitos humanos. Todavia não substituído por elas, pois a própria eficácia desses processos dependem do respeito e (re)configuração da soberania, adaptada às realidades sociopolíticas e econômicas de cada Estado, resultando no reaparecimento de novas tensões entre o direito e a soberania. 


\section{0 direito internacional de águas como limitação à soberania dos Estados}

A distribuição da água no planeta, inclusive dentro do território de vários Estados, é desigual: existem regiões com água em abundância e outras com escassez, o que influencia diretamente nos seus modelos hidrossociais e hidroecológicos. Em razão da sua essencialidade para múltiplos usos, desde os primórdios, a água sempre foi motivo de conflitos, guerras e cooperação entre os povos.

Segundo dados da Organização das Nações Unidas (ONU/PNUMA) disponibilizados em 2003, o desenho hidrográfico mundial conta com 263 bacias hidrográficas internacionais, as quais atravessam dois ou mais países, que concentram, aproximadamente, $40 \%$ da população mundial; sendo que 145 países têm parte do seu território em uma bacia hidrográfica internacional e 21 países estão inteiramente dentro de bacias hidrográficas internacionais, assim distribuídas: 69 estão na Europa; 59, na África; 57, na Ásia; 40, na América do Norte; e 38, na América do Sul. Tal cenário hidrográfico guarda não apenas um mosaico de valores socioculturais e hidroecológicos ocultados da percepção comum, mas também elementos para compreender a construção climática e geopolítica do mundo contemporâneo, uma vez que parte significativa da população mundial depende desses recursos hídricos para a satisfação das suas necessidades vitais e manutenção do modelo socioeconômico.

Dada a preocupação da comunidade internacional em promover a mitigação de conflitos internacionais pelas águas compartilhadas, resultaram construídos diversos diplomas internacionais que produziram as principais fontes do direito internacional de águas.

Até o limiar da década de 1960, os interesses dos países em relação às águas transfronteiriças se limitavam, basicamente, a regular as relações de navegação e produção de energia hidrelétrica. Em razão do desenho hidrográfico europeu, o primeiro diploma internacional a tratar sobre as relações de soberanias dos Estados com o meio ambiente - inclusive, com a água - fora do eixo navegação e produção de energia, foi a Convenção de Estocolmo, de 1972. Depois da Convenção de Estocolmo, diversos outros Tratados e Convenções internacionais foram produzidos abordando outras temáticas relativas à gestão das bacias hidrográficas internacionais. Na Convenção do Rio de Janeiro, de 1992, a questão das águas e das bacias hidrográficas resultaram destacadas com maior ênfase, haja vista a preocupação da comunidade internacional em relação ao uso racional da água em razão do aumento da sua demanda decorrente do aumento da densidade demográfica.

Não obstante a importância das contribuições produzidas pelos diversos Tratados e Convenções internacionais na formação das bases principiológicas do direito internacional de águas, bem como diretrizes programáticas acerca do uso racional da água, no que tange à gestão das bacias hidrográficas internacionais e à relação de respeito aos direitos dos demais Estados vizinhos, especial destaque merece a ConvençãoQuadro de Nova lorque, de 1997, realizada no âmbito das Nações Unidas, quando tratou sobre o "Direito dos Cursos de Água Internacionais para fins Diversos da Navegação". A relevância do aludido diploma normativo internacional se justifica não apenas porque referendou as bases principiológicas do direito internacional de águas construídas até então, mas, sobretudo, porque também provocou a necessidade da revisitação quanto à interpretação da extensão da "soberania" pelos Estados que compartilham as suas bacias hidrográficas.

Destarte, essa temática, que até então se encontrava discutida de forma genérica, superficial e burocrática no plano diplomático internacional e limitada, especialmente, nas discussões por ambientalistas e profissionais da área da navegação e hidroeletricidade, com o advento da referida Convenção-Quadro, passou a revelar a necessidade de novas orientações hermenêuticas quanto à extensão do conceito de soberania dos Estados, sobretudo sua adequação com as diretrizes programáticas acerca da gestão hídrica nas bacias hidrográficas transfronteiriças.

Assim, com fundamento em diversos diplomas internacionais, a Gestão Integrada dos Recursos Hídricos Transfronteiriços (GIRHT) passou a se tornar tema frequente nas pautas das agendas políticas internacionais, razão pela qual foi elencada como um dos objetivos do desenvolvimento sustentável (6.5 
ODS) estabelecidos na Agenda 2030, a qual foi ratificada e internalizada às políticas programáticas de diversos Estados.

O direito à água é um direito humano universal e expressão do princípio da dignidade da pessoa humana. O direito de águas, por sua vez, constitui-se em ramo do direito, sendo espécie do direito ambiental, tendo por finalidade viabilizar o direito à água. Segundo Pompeu (2006, p. 677), o direito de águas constitui ramo híbrido da ciência do direito pelo fato de conter tanto normas de direito público como de privado. Nesse sentido, o aludido doutrinador averba que o direito de águas representa:

\begin{abstract}
O conjunto de princípios e normas jurídicas que disciplinam o domínio, o uso, o aproveitamento, a conservação e a preservação das águas, assim como a defesa contra suas danosas consequências. De início, denominava-se Direito Hidráulico. A estreita vinculação das normas jurídicas relativas às águas com o ciclo hidrológico, que praticamente desconhece limites no seu percurso, faz com que o Direito de Águas contenha normas tradicionalmente colocadas tanto no Direito Privado como no Público.
\end{abstract}

Granziera (2014, p. 12), por seu turno, define o direito de águas como sendo: "O conjunto de princípios e normas jurídicas que disciplinam o domínio, as competências e o gerenciamento das águas, visando ao planejamento dos usos, à conservação e à preservação, assim como a defesa de seus efeitos danosos, provocados ou não pela ação humana".

Apresentados os conceitos sobre o direito de águas pela doutrina pátria especializada, é possível conceber que o direito internacional de águas é um ramo do direito internacional ambiental, uma vez que é condicionado a tratativas políticas e diplomáticas entre Estados soberanos, bem como fundado em Tratados e Acordos internacionais ambientais. Dessa forma, o direito internacional de águas é composto por normas e princípios emprestados pelo direito internacional ambiental, tendo como objeto de fundo a difusão de políticas internacionais de gestão hídrica, para efeito de orientar os Estados na formação das suas políticas hidrossociais, hidroecológicas e de gestão das águas.

Dotado de forte carga principiológica emprestada pelo direito internacional ambiental, o direito internacional de águas, para efeito da consecução dos seus objetivos, resgata, destacadamente, os princípios da proteção, da cooperação internacional e da participação, uma vez que tais princípios constituem os vértices para a governança hídrica, um dos requisitos para a GIRHT.

Nessa esteira, primeiramente, cumpre destacar o princípio da proteção. Esse princípio representou um dos pontos de partida para estabelecer limites à soberania dos Estados, os orientando a adotarem medidas preventivas no sentido de evitarem a repercussão dos efeitos nocivos das suas atividades sobre os territórios dos Estados vizinhos.

Fundamentado em norma de direito internacional ambiental, o princípio da proteção está elencado, expressamente, no Princípio 21 da Declaração de Estocolmo, de 1972, o qual estabelece que:

[...] os Estados têm o direito soberano de explorar seus próprios recursos, de acordo com sua política ambiental, e a responsabilidade de assegurar que suas atividades levadas a efeito, dentro de sua jurisdição ou sob seu controle, não prejudiquem o ambiente de outros Estados ou zonas situadas fora do limite de jurisdição nacional.

Portanto, segundo se infere do referido princípio, ele estabelece limitações ao poder soberano dos Estados, cabendo aos mesmos zelarem pelo controle das atividades causadoras de impactos ambientais em seus territórios e assegurarem que não comprometam a higidez ambiental dos Estados vizinhos. Nessa senda, defendendo um controle da liberdade ou uma liberdade relativa dos Estados, decorrente das suas soberanias para a exploração dos recursos naturais, enquanto corolário do Princípio 21 da Declaração de Estocolmo, Machado (2014, 1.261) afirma:

Desse princípio da Declaração de Estocolmo decorre claramente que os Estados têm uma liberdade relativa ou uma liberdade controlada para a exploração dos seus recursos naturais. Nesse sentido, entende-se que a soberania cria para os Estados obrigações que são corolário de seus próprios direitos. 
No entanto, embora haja o reconhecimento formal do princípio da proteção pelos Estados, não é difícil identificar a sua falta de efetividade no contexto internacional contemporâneo. No que tange às águas de curso internacional, observa-se contínuas e flagrantes violações ao princípio da proteção, haja vista a negligência (ou conivência) dos próprios Estados em relação à falta de fiscalização das atividades dentro dos seus territórios, sendo mais emblemáticos os casos da contaminação hídrica por defensivos agrícolas e outros metais pesados decorrentes da agricultura e da mineração, respectivamente, dentre outros tantos que acabam provocando danos nas águas que correm para os Estados à jusante.

Outro princípio de direito internacional ambiental merecedor de destaque constitui o princípio da cooperação internacional. Esse princípio tem como objetivo o desenvolvimento de estratégias conjuntas entre os Estados, através da transferência de recursos materiais, tecnológicos e humanos de um Estado para proteger o meio ambiente e a saúde humana de outro mais vulnerável. Nesse sentido, o princípio da cooperação se encontra preconizado no Princípio 14 da Convenção de Estocolmo, o qual estabelece que: "Os Estados devem cooperar de forma efetiva para desestimular ou prevenir a realocação e transferência, para outros Estados, de atividades e substâncias que causem degradação ambiental grave ou que sejam prejudiciais à saúde humana".

A importância desse princípio em relação à gestão das águas é tão significativa que se permite pensálo como elementar no que diz respeito à GIRHT, pois é por força da responsabilidade comum - porém, diferenciada - entre os Estados desenvolvidos e os subdesenvolvidos, que é viabilizada a transferência de recursos financeiros e tecnológicos para a solução de problemas em relação à gestão das águas de curso internacional. Nesse sentido, Sarlet (2017, p. 226) afirma que:

Considerando as diversas contribuições para a degradação do meio ambiente global, os Estados têm responsabilidades comuns, porém diferenciadas. Os países desenvolvidos reconhecem a responsabilidade que lhes cabe na busca internacional do desenvolvimento sustentável, tendo em vista as pressões exercidas por suas sociedades sobre o meio ambiente global e as tecnologias e recursos financeiros que controlam.

Outro viés do princípio da cooperação internacional tem como escopo a reparação dos danos transnacionais decorrentes de atividades nocivas praticadas dentro do território de um Estado cuja repercussão venha a provocar danos ambientais dentro do território de outro, inclusive estabelecendo o pagamento de indenizações. Nessa senda, orienta o Princípio 22 da Convenção de Estocolmo:

Os Estados devem cooperar para continuar desenvolvendo o direito internacional no que se refere à responsabilidade e à indenização às vítimas da poluição e de outros danos ambientais que as atividades realizadas dentro da jurisdição ou sob o controle de tais Estados causarem a zonas fora de sua jurisdição.

Com efeito, o princípio da cooperação vai muito além da responsabilidade do próprio Estado em evitar danos ambientais decorrentes das atividades executadas dentro do seu território que venham a comprometer o meio ambiente e a saúde humana em outro Estado. Tal princípio também reforça a solidariedade internacional, preconizando o compromisso de auxílio a outros Estados quando solicitado a ajudar, reafirmando a tendência e o fortalecimento do direto internacional ambiental na defesa do meio ambiente enquanto bem jurídico difuso e supranacional.

Por derradeiro, cumpre-se destacar o princípio da participação. Enquanto consectário da democracia, o princípio da participação oferece oportunidade aos cidadãos de criticarem e participarem nos processos de decisões sobre as políticas públicas, demandando publicidade, informação e transparência em relação à gestão da coisa pública. A sua importância nas questões ambientais foi objeto de destaque no Princípio 10 da Declaração do Rio de Janeiro, de 1992, cujo teor consigna:

A melhor maneira de tratar questões ambientais é assegurar a participação, no nível apropriado, de todos os cidadãos interessados. No nível nacional, cada indivíduo deve ter acesso adequado a informações relativas ao meio ambiente de que disponham as autoridades públicas, inclusive informações materiais e atividades perigosas em suas comunidades, bem como a oportunidade de participar de processos decisórios. Os Estados irão facilitar e estimular a conscientização e a participação pública, colocando 
a informação à disposição de todos. Deve ser proporcionado acesso efetivo a mecanismos judiciais e administrativos, inclusive no que se refere à compensação e reparação de danos.

Referendando a importância do princípio da participação ao discorrê-la como fundamento da democracia participativa, Canotilho (2003, p. 288) averba que:

\begin{abstract}
O princípio democrático não se compadece com uma compreensão estática de democracia. Antes de mais, é um processo de continuidade transpessoal, irredutível a qualquer vinculação do processo político a determinadas pessoas. Por outro lado, a democracia é um processo dinâmico inerente a uma sociedade aberta e activa, oferecendo aos cidadãos a possibilidade de desenvolvimento integral e de liberdade de participação crítica no processo político em condições de igualdade económica, política e social (cfr. CRP, art. 9\%/d).
\end{abstract}

O princípio da participação está umbilicalmente ligado à governança hídrica, a qual, pela sua importância, será mais bem analisada, posteriormente. O princípio da participação, enquanto princípio basilar do direito ambiental e também do direito de águas, não apenas orienta a formação da governança quanto à gestão das bacias hidrográficas, mas também estabelece uma diretriz democrática na gestão, com a participação de entes governamentais, organizações sociais e da sociedade civil, no sentido de desenvolverem políticas hídricas para a solução dos problemas existentes na bacia. No Brasil, esse princípio é materializado dentro da política de gestão de recursos hídricos através dos Comitês de Bacias Hidrográficas (CBH), plataforma em que os personagens acima citados identificam, discutem e apresentam propostas de ordenação para a solução dos problemas relativos ao uso das águas de uma bacia hidrográfica localizada dentro do território nacional, como expressão da soberania do Estado sobre as águas que se encontram dentro do seu território.

Todavia, enquanto norma de caráter nacional, problemas quanto à efetividade do princípio da participação se apresentam no que tange às bacias hidrográficas transfronteiriças, pois estão condicionadas às habilidades hidrodiplomáticas de cada país. Segundo preconizam as leis de todos os países, as regiões de fronteiras são consideradas áreas de segurança nacional e, portanto, marcos reafirmatórios das suas respectivas soberanias territoriais. Por isso que, para a gestão das bacias hidrográficas compartilhadas, são exigidas autorização dos respectivos governos centrais, mediante Tratados ou Acordos Específicos, o que torna demasiadamente complexa a constituição de um Comitê de Bacia Hidrográfica $(\mathrm{CBH})$ nas referidas bacias, como ocorre no Brasil, segundo versa o parágrafo único do art. 37 da Lei 9.433/97, o qual estabelece que "a constituição de Comitês de Bacia Hidrográfica em rios de domínio da União será efetivada por ato do Presidente da República". A título de ilustração, visando demonstrar a complexidade para a formação da governança hídrica nas bacias transfronteiriças brasileiras, tal matéria ainda é regulamentada pela Resolução $n^{\circ} 5$, de 10 de abril de 2000, do Conselho Nacional de Recursos Hídricos (CNRH), a qual estabelece uma série de exigências, não raramente impraticáveis, no âmbito regional.

Conforme se percebe, o emaranhado de normas e procedimentos burocráticos torna o caso brasileiro emblemático, o que talvez justifique o Brasil ter tanta dificuldade em viabilizar a gestão integrada dos recursos hídricos nas suas bacias compartilhadas com outros Estados.

Assim, em que pese o robusto arcabouço jurídico internacional existente em relação ao direito internacional de águas, a efetividade das normas esbarra no poder soberano dos Estados que compartilham as suas bacias, resultando disso problemas hidrossociais e hidroecológicos incomensuráveis. Os Estados são soberanos, tendo o poder e a legitimidade para se autogovernarem, não se submetendo a outros Estados. Todavia a soberania não pode ser interpretada como ilimitação de poder, pois encontra limitações estabelecidas pelo direito, sobretudo pelos princípios e regras de direito internacional, conforme acentuado por Bobbio (1997, p. 101) ao afirmar que "todo Estado existe ao lado de outros estados numa sociedade de Estados", o que condiciona a legalidade dos atos de governo de um Estado como expressão da sua soberania externa, pois somente quando, e desde que, respeitados os direitos dos demais Estados soberanos. Aqui se apresenta o ponto nevrálgico de uma nova antinomia entre o direito e a soberania, sobretudo no que diz respeito à governança hídrica em bacias hidrográficas transfronteiriças como elemento para a consecução da gestão integrada dos recursos hídricos nessas bacias, temática que será analisada na seção seguinte. 


\section{Governança: o desafio para a gestão integrada dos recursos hídricos transfronteiriços}

Enquanto expressão do princípio da participação no desenho e execução das políticas de gestão, o conceito de governança é complexo, amplo e dinâmico. Todavia, independentemente da sua interpretação, necessariamente requer um olhar sociopolítico, representando orientações estratégicas tanto para o setor privado como para o setor público.

A governança tem a sua origem nos estudos das organizações, sejam privadas, enquanto governança corporativa, sejam públicas; tendo como espectro espacial a governança global e a governança local. As primeiras experiências relativas ao estudo de um modelo de governança se deram no âmbito do setor privado, enquanto política corporativa destinada ao alcance dos objetivos das empresas. Posteriormente, sobretudo no decorrer do século XX, após a Segunda Guerra Mundial e em decorrência da crise de desconfiança e transparência de algumas das decisões dos governantes dos Estados, a governança passou a ser estudada enquanto instrumento fomentador da participação social, visando atacar a crise de legitimidade estatal.

Cumpre destacar que o fenômeno da globalização e a evolução dos mecanismos de comunicação por meio de ferramentas tecnológicas culminaram por fortalecer os instrumentos da governança originariamente estudada. O contexto tecnológico hodierno de disseminação da informação pelos meios de comunicação, dotado de capacidade de promover um panóptico global de acompanhamento das decisões dos Estados, redesenhou a criação de novas formas de participação não formal em relação ao desenvolvimento e implementação das políticas públicas.

Especificamente quanto à expansão do termo governança para o setor público, Mata Diz e Moura (2016, p. 65) afirmam que a expressão passou a ser "largamente associada a outros adjetivos, e não apenas corporativa, sendo intensamente empregada nas relações internacionais". Nessa seara, passam a dispensar atenção aos modelos de governança classificados como governança global e governança local.

No que tange à governança local, Mata Diz e Moura (2016, p. 68) aduzem que o nível local consiste, "primeiro e antes de todos, na delimitação físico-jurídica mais necessitada de tal modelo de interação", justificando algumas razões:

[...] a uma, porque grande parte dos pleitos de indivíduos, sozinhos ou em grupos constituídos, é absorvida pelo viés do interesse local; a duas, tendo em vista a maior proximidade dos partícipes da governança local em relação aos destinatários de seus resultados; a três, considerando o governo local um dos atores desse paradigma relacional e geralmente o mais frágil do ponto de vista econômico no modelo de organização do Estado de que faz parte, há que se considerar, especialmente, nas ações por ele perpetradas, as possíveis parcerias com o setor privado e o terceiro setor.

Com efeito, a governança local constitui o modelo mais importante sob o ponto de vista de política social localizada, pois são nas regiões e nas cidades que as pessoas, efetivamente, vivem e experimentam todos os problemas decorrentes das realidades cotidianas, por isso é o modelo participativo de controle no qual as práticas democráticas podem, de fato, serem verificadas.

Todavia, em que pese a inteligência desse modelo de participação, o alcance dos objetivos da governança local, não raramente, resultam comprometidos pelas limitações à participação dos destinatários das medidas concertadas, provocando não apenas um vácuo entre os direitos e a sua efetividade, como também um déficit de legitimidade democrática na sua produção.

No que tange à Gestão Integrada dos Recursos Hídricos Transfronteiriços (GIRHT), a governança aparece como um dos seus pressupostos. Não obstante a amplitude do conceito de governança enquanto condição para a (GIRHT), tal conceito demanda a apreciação de múltiplas variáveis. Conforme acentuado por Villar (2015), o Group Water Partner (GWP) foi o principal responsável por reinventar a Gestão Integrada dos Recursos Hídricos (GIRH) e difundi-la no âmbito internacional, obtendo amplo apoio das agências internacionais do sistema das Nações Unidas. Nesse contexto, conforme o relatório do GWP (2000, p. 22), a GIRH foi definida como "um processo que promove o aproveitamento e gestão coordenados da água, solo e recursos relacionados, com o fim de maximizar o bem-estar econômico e social de maneira equitativa sem comprometer a sustentabilidade dos ecossistemas vitais". 
Diante da complexidade da temática, estudos técnicos propuseram ações capazes de fomentar uma boa governança para efeito de gestão dos recursos hídricos. Nesse sentido, o CAP-NET/PNUD (2006, p. 15) construiu algumas diretrizes, tais como: a) a determinação dos papéis do Estado em relação aos outros atores e a regulação das titularidades e responsabilidades dos usuários e dos fornecedores de água; b) a construção de parcerias entre governo, setor empresarial, comunidade e organizações voluntárias; c) a prescrição em lei das instituições gestoras governamentais e das suas respectivas competências; d) a busca de formas para garantir o uso sustentável do recurso; e) a análise da situação dos recursos hídricos; f) a instalação de consórcios de atores envolvidos no processo decisório, com representação dos setores da sociedade e equilíbrio de gênero; g) a organização de sistemas de alocação e captação de águas, permissão de descarte de águas residuais e bancos de dados; $h$ ) a gestão de recursos hídricos baseada na bacia hidrográfica; i) estruturas organizacionais em nível de bacia e sub-bacias para possibilitar a tomada de decisão no nível mais baixo que for possível; j) a elaboração de planos para a GIRH com base em uma abordagem multissetorial na participação dos atores.

A par dessas orientações é possível compreender a dimensão da complexidade para viabilizar, no plano prático, a governança para uma GIRH, uma vez que demanda a combinação de múltiplos fatores políticos, científicos e tecnológicos, não raramente inacessíveis diante das realidades políticas, sociais e econômicas dos Estados, sobretudo os subdesenvolvidos. No que tange às bacias hidrográficas compartilhadas, tal complexidade quanto à constituição da governança ganha mais robustez em razão da soberania, o que torna inviável a GIRHT sem uma articulação hidrodiplomática para a celebração de Tratados e Acordos internacionais específicos entre os Estados sobre a bacia hidrográfica transfronteiriça.

\section{Conclusão}

O sentido de soberania sempre foi tema nevrálgico para o direito. Na verdade, a soberania e o direito constituem faces opostas da mesma moeda, pois, embora estejam umbilicalmente ligados, a soberania é a negação do direito e o direito é a negação da soberania em uma relação de desafios constantes. Essa tensão existente entre os dois extremos é fruto da natureza de ambos: a soberania, como representação de poder, desafia a observação das regras; o direito, por sua vez, enquanto conjunto de regras destinadas ao bem-estar social, reclama limites à soberania. Por isso, diante do sentido axiológico da água, enquanto bem jurídico supranacional, permite-se defender a limitação do sentido de soberania "absoluta", pautada por delimitações ortodoxas, rígidas e intransponíveis, para um conceito relativizado, mais "líquido" e condizente às demandas da sociedade, desde que as políticas de gestão respeitem os valores constitucionais e os Tratados internacionais, como no que diz respeito ao direito internacional de águas, o qual preconiza certa limitação à soberania dos Estados nas bacias hidrográficas transfronteiriças.

Enquanto expressão do direito internacional de águas, a Gestão Integrada dos Recursos Hídricos Transfronteiriços (GIRHT) encontra obstáculos que parecem intransponíveis no plano da efetividade, pois, além do receio de ameaça à soberania dos Estados nas bacias compartilhadas, também ensejaria reformas no ordenamento jurídico dos Estados no sentido de padronizá-las para evitar o conflito entre suas respectivas normas internas. Em suma, além da soberania, os problemas transfronteiriços decorrem da forma como se organizam as estruturas nacionais e regionais de governança, e das normas que disciplinam a gestão e uso dessas águas. Como consequência, o arcabouço jurídico e principiológico do direito internacional de águas padece pela falta de efetividade no plano da realidade. As principais estratégias postas no desafio da efetividade são os acordos internacionais, celebrados entre os Estados que partilham as bacias transfronteiriças, para a criação de organismos que viabilizem a governança hídrica local, visando promover a gestão conjunta, o que requer profundas articulações políticas e habilidades hidrodiplomáticas.

Apesar dos esforços da comunidade internacional, as políticas para a construção das governanças hídricas capazes de viabilizar a gestão nas bacias hidrográficas transfronteiriças ainda são lentas e enfrentam constantes dificuldades no plano da efetividade. 
Não obstante estarem situadas em regiões caracterizadas como de segurança nacional, entende-se que a melhor governança para uma bacia hidrográfica transfronteiriça é a local, ou seja, organizada pela sociedade local dos Estados que constituem a fronteira, pois é a sociedade que, efetivamente, experimenta e convive com os problemas cotidianos decorrentes da ausência de gestão e regulação pelos respectivos governos centrais em relação aos usos das águas na bacia hidrográfica. A governança e a GIRHT podem tanto inserir mais atores para democratizar a gestão com base nos princípios da proteção, cooperação e da participação, como também servir a interesses disfarçados, mediante processos de tomada de decisões que se dizem participativos, todavia despidos dessas intenções, o que justifica irrestrita transparência em relação ao seu modelo de organização.

Por derradeiro, feitas todas essas considerações, permite-se conceber que deslocar a ideia da GIRHT do plano da utopia, estabelecendo como se materializa a sua aplicação prática e se atinge a boa governança, enquanto expressões do direito internacional de águas, é um desafio que requer mais do que uma conjugação de esforços técnicos, científicos, investimentos financeiros e habilidades hidrodiplomáticas. Isto requer e coloca à prova a demonstração do amadurecimento e capacidade do direito internacional em remover os obstáculos impostos pela soberania dos Estados nas bacias hidrográficas transfronteiriças, rediscutindo velhas e revelando novas antinomias entre o direito e a soberania, as quais tendem a se acentuar no decurso do século XXI por uma simples e fundamental razão: a água.

\section{Referências}

BAUMAN, Zygmound. Globalização: as consequências humanas. Tradução Marcus Penchel. Rio de Janeiro: Jorge Zahar, 1999.

BOBBIO, Norberto. Estado, governo e sociedade: para uma teoria geral da política. Tradução Marco Aurélio Nogueira. Rio de Janeiro: Paz e Terra, 1997.

BODIN, Jean. Los seis livros de la Republica. Tradução Pedro Brava Gala. 2. ed. Madrid: Tecnos, 1992. v. I.

BRASIL. Conselho Nacional de Recursos Hídricos - CNRH. Resolução nº 5, de 10 de abril de 2000. Diretrizes para a formação dos comitês de bacias hidrográficas. Diário Oficial da União, Poder Executivo, Brasília, DF, 11 abr. 2000.

BRASIL. Lei n 9.433, de 8 de janeiro de 1997. Institui a Política Nacional de Recursos Hídricos. Diário Oficial da União, Poder Executivo, Brasília, DF, 9 jan. 1997.

CAETANO, Marcello. Manual de ciência política e direito constitucional. 6. ed. Lisboa: Coimbra: Almedina, 1970.

CANOTILHO, J. J. Gomes. Direito constitucional e teoria da constituição. Coimbra: Almedina, 2003.

CAP-NET, PNUD. Planejamento para a gestão integrada de recursos hídricos. Manual de Capacitação e Guia Operacional. Training Material CD, 2006.

DANTAS, Juliana Oliveira Jota. A soberania nacional e a proteção ambiental internacional. São Paulo: Verbatim, 2009.

FERRAJOLI, Luigi. A soberania no mundo moderno. São Paulo: Martins Fontes, 2002.

GLOBAL WATER PARTNERSHIP - GWP. Manual para la gestión integrada de recursos hídricos en Cuencas, 2009. Disponível em: https://www.rioc.org/IMG/pdf/RIOC_GWP_Manual_para_la_gestion_ integrada.pdf. Acesso em: 26 jul. 2018.

GRANZIERA, Maria Luiza Machado. Direito de águas: disciplina jurídica das águas doces. São Paulo: Atlas, 2014.

INTERNATIONAL WATER LAW. UN Convention on the Law of the Non-navigational Uses of International Watercourses [Convenção de Nova York]. New York, 1997. Disponível em: http://www. internationalwaterlaw.org/documents/intldocs/watercourse_conv.html. Acesso em: 20 jun. 2018. 
MACHADO, Paulo Affonso Leme. Direito dos cursos de água internacionais. São Paulo: Malheiros, 2009.

MACHADO, Paulo Affonso Leme. Direito ambiental brasileiro. São Paulo: Malheiros, 2014.

MATA DIZ, Jamile Bergamaschine; MARTINS, Thiago Penido. Por uma reinterpretação dos elementos do Estado a partir da criação e consolidação dos processos de integração regional. In: ENCONTRO NACIONAL DO CONPEDI, 14., 2015, Florianópolis. Anais [...] Florianópolis: CONPEDI, 2015.

Disponível em: https://www.conpedi.org.br/publicacoes/c178h0tg/p2qwwuu8/19Rek3fjGRjPe2cF.pdf. Acesso em: 13 abr. 2018.

MATA DIZ, Jamile Bergamaschine; MOURA, João Ricardo Fidalgo de. Apontamentos sobre o conceito de governança e sua adoção pela União Européia. In: MATA DIZ, Jamile Bergamaschine; SILVA, Alice Rocha da; TEIXEIRA, Anderson Vichinkeski (org.). Integração, Estado e Governança. Pará de Minas: Universidade de Itaúna, 2016. p. 62-82.

ORGANIZAÇÃO DAS NAÇÕES UNIDAS. Agenda 2030 - Objetivos do Desenvolvimento Sustentável 2030. Disponível em: https://nacoesunidas.org/pos2015/ods6/. Acesso em: 04 ago. 2018.

ORGANIZAÇÃO DAS NAÇÕES UNIDAS. Declaração da Conferência das Nações Unidas sobre Meio Ambiente Humano [Convenção de Estocolmo]. Estocolmo, 1972. Disponível em: http://www.onu.org. br/rio20/img/2012/01/estocolmo1972.pdf. Acesso em: 05 maio 2018.

ORGANIZAÇÃO DAS NAÇÕES UNIDAS. Declaração do Rio de Janeiro sobre Meio Ambiente e Desenvolvimento [Convenção do Rio de Janeiro]. Rio de Janeiro, 1992. Disponível em: http://www. onu.org.br/rio20/img/2012/01/rio92.pdf. Acesso em: 5 mar. 2018.

ORGANIZAÇÃO DAS NAÇÕES UNIDAS. Programa das Nações Unidas para o Meio Ambiente. Perspectivas del Medio Ambiente Mundial. Genebra: GEO-3 Data Compendium, 2003.

POMPEO, Cid Tomanik. Águas doces no direito brasileiro. In: REBOUÇAS, Aldo da Cunha et al. (org.). Águas doces no Brasil: capital ecológico, uso e conservação. 3. ed. São Paulo: Escrituras, 2006. p. 677-717.

REALE, Miguel. Teoria do direito e do estado. São Paulo: Saraiva, 2002.

SARLET, Ingo Wolfgang. Princípios do direito ambiental. São Paulo: Saraiva, 2017.

SILVA, Solange Teles da. O direito ambiental internacional. Belo Horizonte: Del Rey, 2010.

VILLAR, Pilar Carolina. Aquíferos transfronteiriços: governança das águas e o aquífero Guarani.

Curitiba: Juruá, 2015.

Recebido em: 22/09/2018

Aprovado em: 21/12/2018 